\title{
Study on Generation and Development of Social Prediction System
}

\author{
Shuying $\mathrm{Wu}^{1}$ \\ ${ }^{1}$ Shanghai University, Shanghai, China \\ Correspondence: Shuying Wu, Shanghai University, Shanghai, China. \\ Received: February 10, 2021 \\ Accepted: March 20, 2021 \\ Online Published: April 6, 2021 \\ doi:10.5430/jms.v12n1p36 \\ URL: https://doi.org/10.5430/jms.v12n1p36
}

\begin{abstract}
Prediction means predicting future scientifically which has a great relationship with human beings. Based on the development history of prediction system, this paper discusses establishment of modern prediction system and its importance in leadership structure, especially when national prediction system has become a major factor of national security among modern prediction systems. It's just because each country has built a gradually improved prediction system that international political relation could form and stay stabilized. Modern prediction system is now steering to the tendency of controlling the whole social system. In modern society, all the decisions made by institutions depend more and more on prediction and the reform of social system is the soul of predicting the new paradigm of institutional behaviors.
\end{abstract}

Keywords: prediction, social system, generation, development

\section{Historical Development of Prediction System}

In terms of origin and itself, the activity of prediction has nothing to do with science. The reason for the survival of prediction system is superficially the accumulation of personal empirical materials and the continuation of all kinds of activities, underlies which is the decisive condition--- isomorphism of human activities. In terms of development of the mode of thinking and research techniques, prediction activities are inseparable with science. The reason why scientific decision making could appear in modern times superficially depends on accumulation of ideal models and application of different practical approaches, but in essence depends on isomorphism of human activities.

Throughout historical development, there was no disconnection during social progress. Time has never been interrupted as well as historical development, even if repetition exists in the latter one. George Washington was elected as the first president on February $4^{\text {th }} 1789$; two terms after, on March $4^{\text {th }} 1797$ John Adams was elected the second president; In July 1914 the First World War broke out, and after 21years the Second World War broke out in September 1939; Soviet Union experienced the appalling "ritual purges" in 1930s, China went through an unexpected "disaster" in $1960 \mathrm{~s}$; at the beginning of the $20^{\text {th }}$ century, the Third Industrial Revolution took place with the sign of the research of atomic energy and chemical industry; in the mid-twentieth century the Forth Industrial Revolution began marked with the research of high technology; ....How to consider the historical sequence concerns how to understand the turning point of each historical event as well as how to treat future as our orientation of hardworking. As the regaining of people's historical initiative, the whole social system is now in the process of a great reform, and the reform of prediction structure reminds people that it is more important to pay attention to it when concerning about the reform of the whole social system.

What does system render to prediction? There is not such a system without predication and even the simplest system will have the function of predication. It is hardly surprising that system and predication are of the same age. The more we learn about the drive of human predication system, the easier we will perceive that once we treat the human beings as a group, their tremendous potentiality will be released infinitely with the power of system. System presupposes predication's existence and in turn is provided with the possibility of seeking development. Therefore, the analysis of system and predication reflects the research of existence and development to some degree. So the research of the formation of system's prediction mechanism undoubtedly becomes the most perceptual study of human as well as the whole world initially.

Turn to the first page of human history, we realize that human being's existence is the only source of prediction activity's coming into being. It is not difficult to imagine that living in the primeval forest overgrown with weeds, plants and thorny brambles, human beings has to fight the forces of nature fiercely in order to survive. The 
scurviness of objective condition made human pay a terrible price in order to continue their species. The disasters in the past stalked people's heart already and they knew another one would happen unexpectedly sometime. This is the first predication. As they predicted, disaster turned up again. The earliest predication proves its accuracy at the cost of human's sacrifice and suffering, which is also a unique way to continue the predication. You can't imagine a person whose instinct outgrown his or her rationality act as a prophet. The word "prophet" here means the specialized professionals in the modern sense. Nevertheless, the scene represented by human history is: humans still get rid of misfortunes heaps of times before prophets appear although countless disasters are waiting for them. Until today, we realize why the instinct of human's prediction shouldn't be constrained and depressed. Only humans can perceive what they are facing is not only a world full of conflicts, but also an unknown world, while perception which is consistent with the reality is not always rational.

Even the authority couldn't assert that human rationality would exceed their instinct when they began to use lower limbs to walk, because the division of labor between upper limbs and lower limbs is not caused by rationality. If the prediction instinct doesn't exist, the division of labor will has no historical significance. This is tantamount to saying that animals with the labor division of upper and lower limbs will never create a similar history as the human being has done if they couldn't make any prediction. So far, we have found that only some particular animals could imitate a certain behavior of people mechanically and humans are the most complicated species in the biosphere of Earth. What we say here totally rules out the possibility that one day some high intelligent species could replace mankind and take the right of control away from humans. Prediction is unique to human beings.

System is the foundation of prediction. Compared with the prediction activities dominated by rationality, the structural activities based on constant improvement of perceptual systems are not simpler than it. For instance, human body's biological structure had ever aroused our remote ancestor's suspicion. Under the historical condition at that time, witchcraft is the unshakeable ground to verify a certain belief. Then it consigns the patent "know yourself" to the resulting wizards naturally. Divination movement's coming into the open, normalization and the public's acceptance make wizards or people who preside over a celebration, mourning ceremony and all kinds of sacrificial rituals acquire a formidable dignity and social position. People suffer a great loss both in materials and physical strength. They express their wishes by means of prayers and they pray for health, posterity, rainwater, sunshine, food, peace and shelter from the God they worshiped. As all these primitive predication movements have a strong spontaneity, the earliest prediction structure is then simple in personnel organization (few hosts engages in prediction activities), single in organizational level (one tribe is a prediction group), and narrow in field (merely for living need). A predictable problem at that time is: if one wants to rule the tribe, he must control the predication activity first. But if we consider from another point of view, the simple prediction structure is inclined to give rise to administrative power's control over predication activities. It is hardly difficult to understand that simple prediction structure could perfectly illustrate that for a common objective the tribe will be more stable. The narrowness of prediction field demonstrates the chance that any individual tries to live outside the tribe is slim; the simple prediction structure could best explain all the members in the same tribe is of the same rank; the single level of prediction group testifies almost all the people have an equal say; the simple prediction structure explains the social system to which it attaches is not complicated.

The non-administrative role of the person who engaged in prediction movement show human beings' sensibility is greater than their rationality at that time. The change of predication structure makes prediction activity become less spontaneous day by day. Shun (a legendary sage monarch in ancient China) set up an official position "zhizong" (equivalent to supervisor in charge of sacrificial rituals) to preside over the prediction activities, which is a significant adjustment to the prediction structure in practice. The mode that prediction is intervened by administration officially emerges. Prediction is not only a folk activity characterized with spontaneity, but also a system which could consolidate personal domination in a political sense. Shang dynasty establishes a government post "court historian" to be responsible for astronomy, calendar and sacrificial rituals, with subordinated position of "Zhan", "Duobu" and sorcerer taking charge of sacrifices to the Heaven and the Earth. Different from each dynasty, the divination system of Shang Dynasty is all-embracing, from state affairs to private affairs of imperial princes and court ministers. Divination officers are monarch's most important decision-making aides and are given a higher political status. Divination is by no means a decoration because the starts and ends of all activities are closely linked with it. In other parts of the world, dominance hierarchy of some nation considers sacrifices to gods or ancestors as a kind of dominion and they exercise their presiding right collectively. For example, there existed a leadership core between pueblos who lived in Central America (the area in Arizona and New Mexico of America today). It includes one chief leader and three aides, which has the same conditions as in ancient China. Human earliest political system plays a role of leadership in the aspect of governing the prediction activities. More specifically, prediction is the most 
effective way to access leadership as well as a special campaign belongs to top people and organization, while in this point we can't say it is completely the same as modern system.

After human society has stepped into class society, ancient prediction - the difficult task cannot just be completed by instinct, instead, it is taken over by rationality and expands larger and larger in its field. From prediction of natural environment for survival to prediction in the field of economics, politics, military, science and social development, a radical change has happened, but only in a part of the prediction structure. In a fairly long period of time, the significance of the whole prediction structure's change turns to be vital to the authority with the development of the system.

If we say after the production has certain development, general public could live without prediction in a certain period of time, the leaders, especially the top leader, on the country, cannot live without it even in one minute. In the process of "learning about the world" prediction is the final phase, but when entering into the next stage of "changing the world" it becomes societal decision ${ }^{[3]}$. Before modern society, instability of centralization system mainly represented by ups and downs of the leaders in the ruling cliques. Even under the control of government with closed patriarchal clan system, conspiracy and art of vindicating authority, cannibalism and sufferings can hardly be avoided because of the change of leaders. In such a situation, prediction is for the purpose of maintaining the order of ruling, so system's stability depends on prediction naturally. Prediction structure that integrates into social system is complicated. Prediction officer and prediction structure appear for some reasons and needs and it is only when people's mentality and intelligence are inspired that they are seen as instruments to achieve their goals. Once prediction becomes system's demand, there will be a role for it to play in the government body. According to the need, the status of the "role" goes up and down at any time, but the tendency is upward. Incidentally, the status of prediction doesn't decline outside domain of government organization, rather they plays an indispensable function, for instance, the professional prediction institutes in the Temple of Apollo of ancient Greek, the Amun Temple of Karnak in ancient Egypt and the temple of Jerusalem in ancient Palestine. Although all these religious institutes for prediction are not in the list of government organization, they have been paid great attention nationwide in ancient times. Rulers take full advantage of these temples' social status and even in modern times the temples still have a great effect, even outstripping its history in some aspects, which shows that although human rationality is based on instinct, ideas and system which conflict with rationality can also generate. So investigation of predication structure shouldn't just focus on organization style of government, instead, the entire fabric of human activity, i.e. the whole social system should be considered. Another interesting prediction group that emerged in the Warring States Period is the wise men who surround the king. From more than 170 countries during the Spring and Autumn Period to the five hegemons in the early years of the Warring States, every rulers realized that the emergence of the five hegemons was the result of appointment of wise men. Guan Zhong, Zhao Shuai, Hu Yan, Li Heng, Wu Qi, Zou Ji, Shen Buhai and ShangYang all contributed ideas and exerted efforts for their lord's hegemony respectively. In fact, they acted as the senior advisor of the king. After $\mathrm{Zi}$ Chan being the prime minister, the weak state of Zheng appointed Feng Jianzi, $\mathrm{Zi}$ Dashu, Gongsun Hui and Pi Chen to form a diplomatic brainpower in order to carry out diplomatic activities perfectly and survive from the two powerful states of Jin and Chu. Each of the four intelligent men has his strong points and Zi Chan always asks for their opinions in regard to the tough foreign affairs according to their speciality. This is a more professional prediction organization of government and can be taken as the early form of diplomatic facility. Han Fei called the foresighted advisors "Xianshi" as they can provide insight into the trend of times. It turns out to be true that man who has got the wise men could conquer the world finally. "Xianshi" are men who can foresee the development and changes of things. Kings are made to treat the wise men with courtesy when the country is faced with a crisis or at the time of military operation, even some aristocratic bureaucracy follow his lord to recruit many advisors at that time. It is a time period when satisfaction of instinct converts into luscious intoxication. So it is popular to strive for maintaining scholars in the Warring States Period. But all these wise men are not list into official system, i.e. they manage national affairs without an official position. As far as limited dimension and simplicity of prediction structure, it is historically unprecedented. With the establishment of unified dynasty, this kind of prediction structure cannot meet the needs of centralization of authority. To the emperor, that the whole court functions as a prediction institute cannot be better. Then government officials at various levels will predict the emperor's thoughts at any times. From policy of stability and prosperity of the country to daily routine, all things are arranged in detail. Just as Li Shimin - Emperor Taizong said in Zhenguan the first year (627) when he granted titles to the founders, "Although no distinguished service has been established, they made a great contribution to strategy devising and management of the country as Xiao He had done for his country in Western Han Dynasty (206 B.C.-A.D. 24), so they should be rewarded first ." The above is the overall situation. Hereafter all kinds of prediction institutes turn up with some changes in its structure, which is resulted from the current situation. In Chinese history, 
with the division of civil officer and military officers, career soldiers appears, which means the labor division in military become more and more obvious. Therefore, in the system of central military organization a prediction role engaged in business of royal military and warfare emerged. Later the high development of prediction role led to a developed prediction organization. Emperor of each dynasty owned a great brain trust since the Western Han Dynasty. When Sun Zhongshan became the intern president, he restructured the military system and General Staff Headquarters were established by learning from the western countries. Besides this, during the investigation, we find that with the development of modern science, various forms of prediction roles and prediction organizations formed by these roles will come into being as long as there exists human activities. As commented by Engels. After the birth of science, human come to understand that instinct is just the premise of commanding certain ability, while both the command of the ability of scientific prediction and the construction of prediction system can only be practiced by man who is dominated by his rationality.

\section{The Establishment of Modern Prediction System and Its Significant Function in Social System}

Never think the problem of human survival has been solved with the emergence of high technology. In the age of no technology existed, human were worried about the growth of population. However, when high technology has created a rare miracle, human beings are thrown into another kind of bewilderment: when does the rapid population expansion fall back? After all we only have one earth. After going through the World War Two, people come to realize the simple truth gradually. We should not be indifferent to the only earth. It is beyond doubt that dangers and threats exist everywhere. If we say that it is an interesting historical topic why mankind and the social system that accompanies with her could be like that, then where mankind and the social system will go is a mental load that we can't get rid of. Maybe this is the historical logic when establishing the modern predication system.

Suffice it to say that if the modern prediction system didn't exist, maybe human beings would be extinct already. Although we can't prove this assumption, we can justify that the national behavior pattern appears in the factual international relation should be considered as the product of modern prediction system. Modern prediction system is the system safeguard which could help to avoid catastrophes.

Complicated international relationship, unpredictable stock market, AIDS, which is impossible to defend effectively, fast changing science and technology, escalating arms race, volatile economic shocks, rapidly changing relation between supply and demand, intense regional conflicts, global economic integration, inflation, energy shortage, environment pollution, food shortage and greenhouse effect etc. are all stuffed into modern social system altogether. No matter the winners or the losers, they

Will arrange their future plans with the help of modern prediction system. The original maintenance of the integrity of system has already given place to pursuing the soundness of modern prediction system completely.

Modern prediction system has four levels: 1. Prediction system subordinate to the United Nations. 2. Prediction system under the command of groups of nations. 3. Regional prediction institute. 4. National prediction system.

Modern prediction institute has five properties: 1. In essence, it restricts all kinds of people's behaviors; 2.In its operation process, an enormous amount of information will be dealt with. 3. Means of working and work efficiency can be said to be excellent. 4. It is an important symbol of modern social system. 5. Communications media are the largest prediction institutes. The first property manifests itself by prediction system's restriction to people's behaviors by means of other systems. The second one is represented as the working scope of prediction organization. The third property is embodied by working conditions. The fourth property is represented by a fact that prediction is an integral part of social system. The fifth one is reflected by the concern from the public opinion. In terms of individual prediction role, role of prediction institute and all prediction roles in different levels, including modern prediction function of the entire social system, "prediction syndrome" is their common ground.

What is the relationship between the five properties and the four levels? In short, the five properties are adequately embodied by the prediction role in the four levels. After analyzing the tremendous functions that national prediction system has played in relationship between countries, one could gain a further understanding that the five properties and the four levels are the profile of modern prediction system, and at the same time we could realize how important position the prediction system takes in the leadership system. Because national prediction institute is the foundation of the entire modern prediction system and the other three levels of prediction system are all restricted by it.

Precedents that wrong behaviors give rise to severe consequences have become common knowledge, while knowing about common knowledge doesn't mean one will never violate it in reality. It can be terrifically horrible in the nuclear age. It is ridiculous that human pin their hope of avoiding nuclear war on the leaders' sense of superpowers. Both the arms race after World War Two and no great war happened in the recent fifty years seem miraculous. What 
can guarantee the existence of sense? Agreements written on paper are unreliable. Of all the systems, which system functions as a cushion to diffuse the situation in which wars are going to happen? We believe that in modern prediction system national prediction institute is one of the important supports for international security. National prediction system consists of prediction systems for politics, economics, military, education and health, science, technology and culture and etc. and in each system there are subsystems for prediction in different aspects or professional fields.

Somebody made a statistic analysis that after WWII local wars and regional armed conflicts has never been interrupted and up to now 180 ones has happened and another twenty ones are in process. Definitely, any military warfare will be paid more attention by each country, especially those developed countries. The institutes that concern for the affairs are the prediction systems in each country. For instance, a research study from a country shows that during half a century from 1914 to 1954, predictions for more than 50 wars in 100 are incorrect. Obviously, the big powers had conducted comprehensive research about each war and the prediction mistakes here are measured against a rigid quantitative standard. Such a quantitative standard can just promote the prediction accuracy of each prediction institute.

During WWII, prediction system got a rapid development and the system of organization became sounder and sounder, which led to the efficient operation of the whole social system. Take America for example. WWII broke out in 1939, the year when Franklin Delano Roosevelt served for the second term as the US president. Approved by Congress, Oval Office was set up. Different from common secretary team, it functions as the president's advisory committee which could provide the president with schemes of prediction analysis connected with major issues in international politics, military, economics, and diplomatic relations. Modern prediction institute for military appeared in February 1942 when President Roosevelt used his privilege in wartime to set up Joint Chiefs of Staff. One important function of the institute is to make policies of national defense. In 1947, Joint Chiefs of Staff was made American standing body by United States Congress and from then on it became a national security agent as well as an advisory body officially. Modern prediction for diplomacy emerged in April 1947. In order to make a long-term plan, American Secretary of State George Marshall established a research organization which is now the Policy Planning Staff. It is an American strategic think tank of diplomatic works. In order to analyze prediction for the two systems of military and diplomacy comprehensively and carry out a further coordination, the United States Congress set up National Security Council through legislation. The law states that the main function of National Security Council is to assess the prediction for situation of diplomacy and military and it is the Supreme planning agency of American diplomacy and defense affairs. Definitely, coordinating a huge social system in order to make it work efficiently, a comprehensive prediction system must be built. It seems that American people have formed a good habit of acting upon prediction and the density of prediction network's distribution can best explain it. Other than the prediction institutes mentioned above, among all the organizations of central government, there is almost no department or committee without a specialized prediction institute and in some department or committee there are even several prediction institutes. There are tens of thousands of semi-official prediction organizations besides those official organizations. These organizations are called think tank, for they plays an important role in public policy making. So generally speaking, they are closely related with the government. It is remarkable that all these think tanks involve in a wide domain as far as research subject is concerned, and many organization become famous for their prediction's coming true miraculously. After World War II, developed countries except America established a complete prediction system generally, but the scale is not as large as in America. What made the American people proud is that American government appropriation to Social Science Research increased rapidly. From 57 million dollars in 1959 to 750 million dollars in 1979, it increased more than tenfold during the twenty years. It is worth mentioning that some folk prediction institutes or even prediction institutes in some small countries have already established authority around the world, such as Stockholm International Peace Research Institute in Sweden, London International Institute for Strategic Studies in England and Jane's Information Group. Their prediction accuracy is more often than not superior to the authority.

Just because each country has set up a perfect prediction system with each passing day, the modern international political relations can be formed and stay steady.

During the Cold War, America and Soviet Union attempted to build a system through which general equilibrium could be acquired. Comprehensive equilibrium system accesses to a senior stage during the period when constant rebalance is built. We should say in the immediate stage prediction system provided the possibility that the future of equilibrium system should be paid attention when the two countries kept the state of cold war. Afterwards the stability of the world situation based on the improved relation between America and Soviet Union again manifested that prediction system still plays an irreplaceable part in the process of building an conciliatory international system. 
National prediction system and structure is one of the guarantees of modern international peace. The decisive factor is that national prediction systems in two antagonistic countries could universally acknowledge some specific prediction results. During the peak period of nuclear stockpiles, the explosive power of 40 thousand nuclear warheads stored in America and Soviet Union is one million times stronger than the explosive power of the atom bomb threw in Hiroshima at that time. Prediction institutes not only provided prediction of "Mutually Destruction" for each government, especially for the government of the two nuclear powers, but also made brinkmanship according to the viability theory of a country. Making such a policy per se includes foreseeing the immediate consequence if brinkmanship is carried out and predicting the response of some country or some group triggered by the consequence. For example, a country forebodes that another country potentially poses a threat to it, and then it makes a policy to ask some country for direct protection. The country which makes the policy can't just predict whether the country being asked could provide direct protection and how much the input is; what's more important is to foresee a series of problems precisely aroused by direct protection: whether the joint action by the requesting state and the requested state will induce some reaction of the country which poses a threat, at what speed and to what extent it will react. They must assume worst and anticipate that the threatening country will consider this joint action as a kind of pugnacity. The response of the requesting country and the requested country must be predicted according to the fiercest reaction of the threatening country and only through this response can the decision be made that whether a measure should be taken to change the current situation immediately. It is clear that brinkmanship is a policy contains many specific links and procedures. In order to avoid military fight caused by mistakes in some link, prediction institutes foresee that it is necessary to build a particular channel of communication between the two antagonistic leading powers so as to find out the real purposes and intentions of each other in detail timely on the level of top leaders, i.e. to set up a controllable guideline on upgrade conflict in the unavoidable confrontation. The implementation of the guideline is the mission of modern prediction system, and then in June 1963 America and Soviet Union signed Washington-Moscow Hot Line Agreement. To a certain extent, that was a tremendous flexibility that the two leading powers had represented in the aspect of setting up a new prediction mechanism since Cuban Missile Crisis. It is not enough that peace in the nuclear century just depends on the regular meeting of the leaders, for it is probably that a great crisis will occur during the "regular interval", and the setting-up of "Hot Line" helps to solve this problem. On the "Hot Line" there are telephone operators who can speak both English and Russian fluently all day long, which is necessary for the two countries' leaders to deliver their greatest intention and decision rapidly and precisely. For instance, in 1978, American President Carter and the Soviet leader Brezhnev once used "Hot Line" to express their opinions and exchange requirements in time, which finally eased the Lebanese tense situation. Besides the direct effects of the use of "Hot Line", another psychological function of relieving animosity was operated. When crisis broke out, leaders in America and Soviet Union had thought that they could use "Hot Line" to ascertain intentions of each other, and then make their own plans. If we judge "Hot Line" with word "design" we could explain it in this way: in conditions of lacking of security guarantee, "Hot Line" is the reflex design which could recognize the future situation quickly, i.e. system design of reflex of crisis condition. The establishment of positive reflex prediction system broke the passive reflex closure state in which prediction systems on the country level don't contact directly. Switching from passive reflex to positive reflex is a great improvement when the whole prediction system selects a high goal, and each party's selection of high goals offers a great driving force for the formation and perfection of modern prediction system internally. In modern times, this driving force changed the sequence of the main problems that human beings worried about for their survival.

All this is the result of fierce competition between high goals. High goals must recombine with prediction system. Once the positive reflex prediction system has an outline, modern prediction system will cover multiple prediction entities. For instance, in order to avoid nuclear ward and the sharpening of conflicts, besides the "Hot Line" communication, America and Soviet Union also set up predicted "brake apparatus" which could prevent or stop the acceleration of crisis, such as NRRC (Nuclear Risk Reduction Center), reconnaissance satellite system, Early Warning System in different military services. All these organizations possess a great many professional workers as well as up to date technological equipments, and in order to ensure safety, command system will organized these separate prediction institutes into a net system. For years, this system has undergone all kinds of tests, including false alarms as a result of technical malfunction in some parts of early warning. The most serious one was in June 1980 when the early warning system of American Strategic Air Command raised a false alarm that multiple intercontinental missiles and submarine-launched missiles were flying to America owing to the malfunction of early warning system. Staff on duty sent out a warning and at the same time they got into touch with NRRC. Latter they confirmed that there was something wrong with the system and then they cancelled the alarm of war. People were convinced that Soviet Union would definitely hear the news soon and learn about American response speed to this false alarm, and then predict American second-strike capacity and the effect of first strike. As big powers have 
built modern prediction systems widely there is exchange about prediction between countries. Thus references of development of international politics and the solution of significant practice problems can be put on a practical basis, which is the first objective function that modern prediction system plays in order to look for a way out for international peace.

National prediction system is one of institutional guarantees of national policy-making. National prediction system is one part of social system, which contains two meanings: national prediction organizations penetrate through all fields; organization system in each field has special prediction function. This is also a common phenomenon in modern social system, i.e. one structure performs multiple functions. Social system's requirement for prediction system interacts with design of social system by prediction system, and the consequence is to make, execute a serious of important policies jointly. Institutional guarantee doesn't influence the effect of policy forecasting of prediction system directly, for example, the determination of prediction system and the analysis procedure of policy forecasting can't prevent the releasing of policies which are contradictory with reality. The reason why all kinds of wrong policies are implemented is not because there is no prediction system and we shouldn't misunderstand that the operation of prediction system could put an end to unscientific theories and behaviors. The existence of prediction system means that before making and carrying out a policy the country must learn about and answer a serious of questions, and "learn about and answer" implies how to make and execute the policy. But this is not the process of policy-making itself and it is still far from the actual policy implementation.

However, in recent years there are some important changes in the institutional guarantee function of modern prediction system. Among the changes, the most significant one is that the "institutional guarantee function" has broken through the limitation in form more and more to pursuit the seldom efficiency-standards in the past. Modern prediction system is highly developed not only in the aspect of soundness of organizational structure, but also in the aspect of efficacy of prediction system. National policy plays a crucial role in national efficiency. Policy mistake will bring about a huge waste and even if the policy is carried out by the most efficient executing agency, efficiency loss is the only consequence. The developed prediction system must function as an institutional guarantee to the operation of national efficiency, or it can't be said to be developed. However, in order to do so, two approaches must be adopted at the same time. Firstly, prediction system directly intervenes in the making and execution of the policy, namely, directly predicts what kind of psychological effect the policy will produce to the society, what the outcome is after the implementation of the policy. This kind of "predict directly" is not the initial stage at which general conception of what national policy will be made and carried out (in this stage, prediction system will forecast what kind of national policy should be made and how to put it into effect), instead, it will predict all the imminent results (in this stage national policy has been made and is about to be carried out). Secondly, social system must set up a suit of mechanism in the field where prediction system doesn't function (such as executive agency of national policy which is parallel to prediction department), which is tantamount to saying that a relation between prediction system and administrative system should be established, and the most effective method is that administrative system takes on responsibility of prediction function which can't be extended but can be transferred by prediction system.

\section{To Control the Whole Social System Is the Development Direction of the Function of Prediction System}

In modern society all the decision-making in organizations is now increasingly depending on prediction, so that the boundary between the two becomes fuzzy. The penetration between them makes the position of prediction in regular procedure of decision-making becomes more and more important. Prediction system developed on the basis of restricting the procedure of decision behavior has developed into a system which could restrict the whole process of decision-making now. In other words, modern society can't tolerate the existence of dictatorship in decision-making, and prediction system should become a coercive power that could restrict decision-making. This is the second objective function that modern prediction system has played when it takes the professional responsibility for scientific decision-making. National prediction organization is an important institution of management of national behaviors and leader behaviors. Traditionally, administrative departments and their leaders get used to and prefer to apply administrative power to protect the legality of their behaviors, and leader power owned by individuals is of the first importance since ancient times. Even in modern times, agencies which could restrict administrative organizations and their leaders are either in a condition of not being built and unsoundness or in a condition of being built but with a restricted power. Being an individual leader who is addicted in power, he hopes that there is less restriction to his authority. But a very simple experience casts a shadow on leadership system which functions as a restricted condition: individual power often hampers the smooth function of system of organization but being a given restricted condition, leadership system sometimes accepts the leaders" "obedience" in a negative sense.

Regulating function of national prediction institutes towards national behaviors and leader behaviors becomes 
stronger and stronger with the failure of the behaviors. It is not hard to understand that it is a function of social system which is attached to the highly developed institutional civilization, while system in traditional society faced with problems of modernization is devoid of this ability or barely has any of this ability. So when judging whether a system is developed we have reason to regard it as a sign that whether it has such ability. Using the population threat to the world as an example, crisis of population explosion that underdeveloped countries faced with is much greater than in developed countries. But prediction institutes of population in undeveloped countries take a less regulating effect than in developed countries when alleviating the crisis of population expansion. As relevant prediction departments are under the pressure of the party and government that call for "creating a world miracle", Chinese population policy just considers being appreciated by leaders and then is burdened with a big population figure. According to the population base and growth rate in June 1988, the number of Chinese population will increase 25 in every one minute. However, China just in 1978 showed that she would like to accept the request made by UNFPA (United Nations Fund for Population Activities) of helping China to control the population when China had just joined the UN in 1972. The real and concrete cooperation started in 1982 when national population census was carry out, from which we could see that Chinese leadership system will drop their daydreams only when predictions made by prediction institutes have come true for a long time. But at this moment, leading authority of modernization has been impaired besides the confirmation of predictions. By comparison, it is an altogether different situation in developed countries. Firstly, demographic forecasting organizations in western countries mainly focus on developmental trend of the world population, namely, they research and forecast the population problem of their own country and the world population problem altogether. Secondly, demographic forecasting organizations in western countries will take problems of food, energy, ecology and resources into account when they engage in the research and prediction of the world population problems. Lastly, prediction institutes could rapidly notify administrative organizations to carry out the plan designed for population control. It is not hard to imagine that governments of this kind consider forecasts and plans of prediction institutes as inviolable instructions and they could go through the tough period of population growth. For example, governments in developed countries adopt effective measures to control the population and rate of population growth in West Europe and North Europe is almost zero or has already entered into the stage of negative growth. Growth rate of population in East Europe, America and Japan has already dropped greatly.

The more developed the social system is, the sounder the prediction institute is. The result must be the constant promotion of the prediction institute and its function in the whole social system. Modern prediction system is now in the process of orientating itself towards the control of the whole social system. The obsolete method of strengthening the regulating function was at the cost of the failure of the national behavior and the leader behavior and now it is believed to be a great loss or even a choice of self-destruction. The key point of shifting to a new paradigmis the development of forecasting function and neither the increase in the number of prediction institutes nor the adjustment of prediction institutes is a critical factor, but the change of the environment of the social system counts a lot. Investigating the function of prediction system should start from its corresponding social system, government system, party system and state system. It is the institutional environment of prediction system.

Forecasting structure determines part of the prediction function and increase or decrease in the number of the prediction institutes will also influence part of the prediction function. However, all these are non-crucial factors to the continuous progress of prediction system. Forecasting environment determines forecasting structure, the quantity of prediction institutes as well as part of the forecasting function that can't be determined by forecasting structure or the quantity of prediction institutes. Whether the prediction system is effective depends on what function it has. In fact, judging whether various kinds of systems are effective one should firstly check what function it possesses. It is the same with judging the function of the system environment. The function of the whole system environment has a special effect to the function of prediction system, and using such a special effect to explain the function of prediction system can best illustrate the conflicts between paradigms of prediction system. Division of powers and checks and balances is a kind of authority pattern and division is for the purpose of checks and balances. System division is one function of prediction system, i.e. system forecast. System division per se is a kind of system forecast. Operation mechanism of social system is a resultant force of many behaviors of systems in the society and system division is the representation of the internal relation of this resultant force. If result of system prediction embodies the necessary relationship of the internal relation of this resultant force, not only system prediction succeeds and prediction system becomes a power in the check and balance, but also check and balance of the whole system will turn into the basic norm of social subjects timely because of the foundation of new paradigm of prediction system. The necessity of the division of social system determines the essentiality of check and balance of system and further determines the logical development of system prediction as well as the causal behavioral pattern of prediction 
system.

Between prediction system and system prediction, behavioral norm of prediction organization is an indispensable link. This norm can either be considered as logic development of prediction system or system order of system prediction. System prediction means a conception that starting from institutional structure prediction system divides and determines the sphere of influence and form of system authority. Besides forecasting the development of specific objects, modern prediction system must forecast the evolution of the whole system. When analyzing and investigating the internal relations of systems, inner connection between behavioral norms of prediction system and all the other systems are definitely involved. Paying attention to institution-building interaction between system behaviors should be stressed. Behavioral norms of systems are in symbiotic relationships but symbiotic doesn't mean they are coordinated with each other. The difficulty in the building of effective behavioral norms of prediction system exactly rests with translating these behavioral norms into widely accepted social right. One should know that prediction system is a social protection system created for avoiding multiple disasters. As inefficient prediction system is often unable to translate itself into a motivation which could affect other systems, operation of many systems then traps into internal friction, while duration of internal friction signifies inevitability of catastrophes. On March 14, 1989, United States Food and Drug Administration discovered two of the seedless red grapes imported from Chile are highly toxic with sodium chloride. Governmental agencies like this kind that has high professionalization possess strong professional prediction function at the same time. Check of imported foods and drugs is also a prediction behavior-estimating the hygienic quality of imported foods and drugs as well as their impact on national health. More than that, once there are problems, such as the two poisonous grapes could enough cause business sector to withdraw the fruit from the market. It is hard for the business sector to imagine that this fruit is going to be sold in the market after the two poisonous grapes are removed, though doing so could prevent some loss. If business sector and transportation sector ignore the instruction of United States Food and Drug Administration, in other words, if behavioral norms of prediction institutes lose their meanings because of the internal friction of other institutes, disaster is just around the corner. The development of society is depends upon the perfect performance of prediction system. Behavioral norms of prediction system shouldn't scrupulously abide by the old paradigm: just predict the future development of things and don't care whether the supposed effectiveness of prediction worth it. The new paradigm of prediction system is supposed to be that behavioral norms of prediction system could launch administrative power and social force at any time to coordinate the relation between all kinds of systems according to the hierarchical structure. We can definitely say many big issues that fall into the field of competition between social systems depend on the competition between prediction systems. That the capability of prediction system to make a comprehensive plan in competition and allocate resources reasonably in every domain matters which social system will charge the result of the competition. Obviously, making a comprehensive plan and allocating resources reasonably rest with the foundation of new behavioral paradigm of prediction system. From the flow of the foundation of institutional structure, solution of new behavioral paradigm of prediction system will benefit much greater than purely solving the problem of prediction flow, while the establishment of coordination mechanism is a necessary cost paid for the solution of new behavioral paradigm of prediction system. The reason for the emergence of new behavioral paradigm of prediction system is that social system must acquire its developmental qualification at a cost less than the historical records to get the same resource. If it fails, the society cannot make a progress. It is just in this sense that reform of social system is the soul of new behavioral paradigm of prediction system.

\section{References}

Boucher, W. I. (1985). Study on Prediction and Future (Vol. 7). Beijing: Scientific and Technical Documentation Press.

Cai, M. D. (1992). Prediction and Decision Making. Beijing: Scientific and Technical Documentation Press.

Ge, E. (1998). An Entire Book of Prediction. Beijing: Beijing City Press.

Gong, J. H. (1998). The Full View of the $21^{\text {st }}$ Century (Vol. 5). Guangzhou: Guangdong Economic Press.

Kosolapov, B. B. (1985). Study on Methodology of Social Prediction, translated by Gu, J.Q. Guiyang: Guizhou People's Publishing House.

Krekon. (1984). Principles of Prediction. Beijing: China Prospect Publishing House.

Qin, L. Z. (1985). Prediction Science: Study of the Future. Guiyang: Guizhou People's Publishing House.

Toffler, A. (1984). Prediction and Presupposition: Toffler - Dialogue in the Future. Beijing: International Culture Publishing House. 
Wang, H. Q. (1998). Mystery of Prediction: Discussion About Prediction (Vol. 7). Beijing: China International Publishing Group.

Zheng, R. Q. (1988). Principles of the Study on Prediction. Beijing: China Statistical Publishing House.

\section{Copyrights}

Copyright for this article is retained by the author(s), with first publication rights granted to the journal.

This is an open-access article distributed under the terms and conditions of the Creative Commons Attribution license (http://creativecommons.org/licenses/by/4.0/). 